\title{
FORMAÇÃO PARA INCLUSÃO DA EQUIPE PEDAGÓGICA DO COLÉGIO MILITAR DOM PEDRO II
} TRAINING FOR THE INCLUSION OF THE TEAM OF THE MILITARY COLLEGE DOM PEDRO II

\author{
Railda Gonçalves', Alessandro Messias Moreira', Guaracy Silva', Sheldon William Silva'
}

\begin{abstract}
Resumo
A educação é um direito assegurado para todos os sujeitos. Dessa forma, o objetivo deste trabalho é verificar como a acessibilidade comunicacional, atitudinal e arquitetônica de uma escola interfere no processo de inclusão das pessoas com necessidades educacionais especiais, bem como, estimular a discussão sobre o tema na perspectiva de contribuir para a qualidade do processo educacional e de oportunizar a análise e reflexão em relação ao assunto. Como proposta metodológica foi realizado um estudo baseado em referenciais teóricos e legislações que sustentam o tema abordado, além da realização de uma pesquisa de campo com alunos, monitores e professores, no intuito de compreender a percepção e os interesses no que se referem a inclusão escolar. A análise dos resultados favoreceu a divulgação interna e subsidiou ações na perspectiva da inclusão, além de que, permitiu a detecção da necessidade de adequação nas práticas pedagógicas, da formação dos profissionais e da readequação da estrutura física para garantir a inclusão.
\end{abstract}

Palavras-chave: Educação Inclusiva. Formação Militar. Formação de Professores.

\begin{abstract}
The education is a guaranteed right for all subjects. Therefore, the objective of this paper is to verify how the communicational, attitudinal and architectural accessibility of a school interfere in the process of inclusion of people with special educational needs, as well as to stimulate the discussion about the subject with the perspective of contributing to the quality of the educational process and to provide analysis and reflection on the subject. As a methodological proposal, a study was carried out based on theoretical references and legislation that support the theme addressed, as well as conducting field research with students, monitors and teachers, in order to understand the perception and interests regarding inclusion school. The analysis of the results favored the internal disclosure and subsidized actions from the perspective of inclusion, besides, it allowed the detection of the need for adequacy in the pedagogical practices, the training of professionals and the adjustment of the physical structure to guarantee inclusion.
\end{abstract}

Keywords: Inclusive Education. Military Formation. Teacher training.

\footnotetext{
${ }^{1}$ Centro universitário do Sul de Minas

E-mail: sheldonwilliamsilva@gmail.com
} 


\section{INTRODUÇÃO}

Um dos desafios da educação inclusiva é assegurar o acesso e a permanência do estudante na escola. Nos últimos anos, ocorreu um importante avanço na legislação que trata sobre o assunto, exigindo nova postura dos sistemas de ensino, da escola, dos educadores e dos alunos na perspectiva de adequarem às reais necessidades inerentes a diversidade humana. Por esse viés, preparar adequadamente a comunidade escolar formando professores, especialistas, analistas, diretores, auxiliares, pais e alunos no caminho da inclusão evidencia-se como fator que contribui significativamente para que todos os envolvidos tenham atitudes coerentes e favoreçam o processo; da mesma forma o cuidado com a arquitetura dos prédios, fará com que a escola se torne um espaço para todos.

Ressalta-se que a Constituição Federal de 1988 traz como um dos objetivos fundamentais o previsto no art. 30, inciso IV, "promover o bem de todos, sem preconceitos de origem, raça, sexo, cor, idade e quaisquer outras formas de discriminação" (BRASIL, 2015, p.11). O Artigo 205 da referida Carta Magna destaca a educação como direito de todos, que deve garantir o pleno desenvolvimento da pessoa, o exercício da cidadania e a qualificação para o trabalho. Dessa forma, o papel primordial da escola sintonizado com a legislação é ofertar um ensino de qualidade e atender a diversidade, considerando que todos os estudantes têm o direito a uma educação de qualidade, independente de possuir ou não alguma necessidade educacional especial.

Partindo dessas premissas, esta pesquisa busca atender alguns objetivos, no sentido de verificar como a acessibilidade comunicacional, atitudinal e arquitetônica de uma escola, interfere no processo de inclusão das pessoas com necessidades educacionais especiais, bem como, estimular a discussão sobre o tema na perspectiva de contribuir para a qualidade do processo educacional e de oportunizar a análise e reflexão em relação ao assunto.

Com o intuito de alcançar os objetivos propostos foi realizado um estudo de campo no Colégio Militar Dom Pedro II - CMDP II, instituição ligada ao Corpo de Bombeiros Militar do Distrito Federal - CBMDF, local este em que foi aplicado questionários a professores, monitores e alunos. Com o acesso aos resultados, foi estimulado a reflexão e discussão a respeito do tema inclusão escolar, além da oferta de formação continuada que tratou a respeito do assunto.

\section{DESAFIOS PARA A EDUCAÇÃO INCLUSIVA}

A promoção da pessoa humana deve acontecer em todos os contextos sociais e de forma peculiar na escola, por meio da oferta de uma educação que promova o sujeito humano, garantindo a ele uma educação de qualidade, capaz de levá-lo para a prática da cidadania e preparação para as atividades laborais (BRASIL, 1996). Assim, tal espaço pressupõe ofertar um serviço que atenda com qualidade todas as pessoas, incluindo alunos com deficiência, com transtornos globais do desenvolvimento e/ou com altas habilidades/superdotação (BRASIL, 2014).

Nessa lógica, analisar a Educação Inclusiva no espaço escolar pressupõe repensar o ambiente, as práticas, as relações, sobretudo, os vínculos estabelecidos entre alunos, professores e demais membros da comunidade escolar.

Prioste (2006) destaca que muitas das limitações perpassam pelas condições de trabalho e pelos estereótipos perante a diversidade. Ou seja, embora existam espaços compartilhados e a escola é um deles, existe também a exclusão, tendo em vista que a subjetividade do outro é considerada estranha mesmo em um local em que deveria ser observada e acoIhida.

Nesse sentido é comum as barreiras que se impõem na operacionalização do processo inclusivo nas mais diversas escolas públicas e privadas do país, que se materializam pela ausência de pessoal especializado, dificuldade frente a prática inclusiva e ineficiência nos processos.

Assim, por mais que exista o substrato legal indicando o que deve ser feito frente a realidade que se apresenta, encontra-se aspectos que escapam tornando a legislação incapaz, por si só, de garantir de uma prática inclusiva que proporcione ao aluno com deficiência o crescimento e a aprendizagem necessá- 
rias, de acordo com suas particularidades.

Neves, Rahme e Ferreira (2019) pontuam que mesmo o substrato legal é incapaz de contemplar a complexidade que tangencia a educação inclusiva, o que dificulta que ela seja realmente para todas as pessoas. A esse respeito, as autoras reforçam que "na busca por oferecer uma educação para todos, por combater incisivamente a desigualdade, enseja-se o risco de apagar a identidade e produzir a indiferença, capaz de configurar como uma nova forma de segregação" (NEVES, RAHME E FERREIRA, 2019, p. 11).

Ou seja, o processo de uma educação inclusiva pressupõe muito mais do que trazer as pessoas com deficiência para dentro do espaço escolar, mas sim em criar condições para que esse sujeito cresça, se desenvolva enquanto pessoa humana, construa sua identidade na relação com os pares do processo educativo e tenha todas as condições necessárias à sua emancipação enquanto sujeito (MOREIRA e CHAMON, 2015).

Por esse viés, a educação torna-se desafiante para a sociedade e para as organizações de ensino, se levado em consideração

[...] o longo percurso de estigmatização social experimentado pelas pessoas com deficiência e a constituição dos espaços segregados. Romper com essa lógica e trabalhar na construção de princípios democráticos que efetivem os direitos sociais dessa população, considerando, para tanto, seu protagonismo, torna esse processo ainda mais desafiador, dada a longa experiência de tutelamento ao qual as pessoas com deficiência se encontravam tradicionalmente subordinadas (NEVES, RAHME E FERREIRA, 2019, p. 12).

É essa a lógica que o Colégio Dom Pedro II se depara, ou seja, com as dificuldades inerentes ao processo inclusivo e a busca por romper com as barreiras que impedem a inclusão de fato, que corrobora com o desenvolvimento do sujeito e que traz oportunidades para o aluno com deficiência, bem como, para os pais, demais discentes e profissionais envolvidos no processo, de forma a proporcionar novos laços sociais.

Voltolini $(2019$, p. 2), por sua vez esclarece que
A criação de uma cultura inclusiva não depende estritamente da criação de leis específicas, mas exige um tipo de engajamento de todos e da dialetização dos impasses e conflitos advindos desse engajamento na direção da construção de um novo tipo de laço social. Esse engajamento não pode ser apenas moral, ou seja, suportado em uma declaração de apoio à causa, mas ético, quer dizer, baseado em um exame de nossas próprias implicações no processo segregativo.

Situação essa que pressupõe a ressignificação de práticas, conceitos e crenças, uma verdadeira quebra de paradigmas na lógica da construção de laços que promovam as pessoas humanas envolvidas. Assim, não é apenas a lei, a moral que fará a inclusão acontecer, mas sim uma mudança na prática e na própria compreensão do sujeito humano, que ultrapasse as leis e chegue a políticas de educação inclusiva que faça sentido e que contemple todas as pessoas.

\section{POLÍTICA DE EDUCAÇÃO INCLUSIVA}

Em consonância com a política educacional, o tema inclusão vem ganhando espaço na comunidade escolar por meio de debates e reflexões, mudanças de práticas e ampliação do conhecimento teórico dos envolvidos diretamente com o processo, principalmente dos professores.

Por sua vez, as políticas públicas em âmbito nacional, estadual e municipal tem sofrido permanentes adequações, visando garantir a inserção de todos no processo educacional, de maneira especial, às pessoas com deficiências. A esse respeito, Montoan e Prieto (2006) lembram que a formação deve ser um compromisso de todos, do sistema de ensino, dos professores, dos gestores e da comunidade escolar. Todos os atores envolvidos devem assegurar uma proposta que corresponda a necessidade humana e de formação constante dos atores envolvidos.

Meirieu (2002) enfatiza que no cenário educacional atual a escola se configura como um espaço de universalização de saberes e da cultura. Nesse sentido faz se necessário que ela atenda à diversidade presente em sua estrutura, em vista da real inclusão escolar. Destaca-se que inclusão não é a inserção da 
pessoa em sala de aula, mas a garantia do aprendizado, do desenvolvimento, das relações humanas e do respeito as diferenças. Escola é também lugar de inserção social, dessa forma ela deve configurar-se como um espaço de reflexão das políticas públicas, principalmente as educacionais, corroborando com a sua aplicação.

No Brasil as reformas políticas na área da educação inclusiva foi avançando gradativamente, considerando que, entre o período da década de 1970 e 1980, houve o processo de institucionalização da educação especial no sistema público de ensino (MAZZOTA, 1995).

A Lei de Diretrizes e Bases da Educação Nacional - LDBEN Lei no 9394/96 traz a Educação Especial como uma modalidade de ensino caracterizada pelo atendimento de natureza complexa, de ação transversal baseada nos princípios da inclusão, que perpassa todas as etapas e modalidades da Educação Nacional (BRASIL, 1996). No Art. 58 da referida Lei, encontra-se que a Educação Especial será "preferencialmente" oferecida na escola regular de ensino, indicando a oportunidade de inserção real na escola e na sociedade, com possibilidade de convivência em espaço que garanta o pleno desenvolvimento (BRASIL, 1996).

Por esse viés, a Lei no 7853/89 assegura o pleno exercício dos direitos individuais e sociais aos alunos com deficiência, transtornos globais do desenvolvimento ou altas habilidades/superdotação. Já o Estatuto da Criança e do Adolescente Lei no 8069/90 (BRASIL, 1996), no seu art. 3ำ, Parágrafo Único destaca que a criança e o adolescente receberão todo 0 atendimento necessário, sem discriminação. $\mathrm{O}$ art. 5o ressalta que "nenhuma criança ou adolescente será objeto de qualquer forma de negligência, ou discriminação [...]" (p.9). Por sua vez, a Lei no 13.005, de 2014, aprovou o Plano Nacional de Educação (PNE), composta de quatorze artigos e vinte metas desdobradas em Estratégias. A meta 4 ressalta a universalização da educação para a população de 4 (quatro) a 17 (dezessete) anos, sendo que esse processo garante aos alunos com deficiência, com transtornos globais do desenvolvimento e com altas habilidades/ superdotação o acesso à educação básica de quali- dade e ao atendimento educacional especializado, preferencialmente na rede regular de ensino.

\section{CARACTERIZAÇÃO DA COMUNIDADE ESCO- LAR DO CMDP II (COLÉGIO MILITAR DOM PEDRO II)}

O Colégio Militar Dom Pedro II foi criado através da Lei Distrital no 2.393, de 07 de junho de 1999 (DISTRITO FEDERAL, 1999), e regulamentado pelo Decreto no 21.298, de 29 de junho de 2000 (DISTRITO FEDERAL, 2000). Por meio da Portaria no 021/CBMDF, de 07 de julho de 2000, publicada no Boletim Geral-BG no128, do Corpo de Bombeiros Militar do Distrito Federal, tem aprovado os Regimentos Interno e Escolar, visando à promoção de um ensino de qualidade.

A organização funcional do CMDP II conta com 187 militares e 197 civis, totalizando 384 pessoas entre servidores do administrativo e do pedagógico. Atualmente o Colégio possui quadro discente de aproximadamente 2.600 alunos na Educação Básica. O CMDP II é uma instituição cuja comunidade escolar é complexa, pois, além de trazer consigo valores militares, atende estudantes de perfis socioeconômicos diversos. Existe também o Serviço de Orientação Educacional, Psicologia e Assistência Social (SOEPAS), composta por uma equipe multidisciplinar responsável pelo desenvolvimento de ações de suporte psicopedagógico e assistencial a todos os segmentos do CMDP II.

O Projeto Político Pedagógico (PPP), datado de 3 de fevereiro de 2011, apresenta uma proposta pedagógica com o intuito de garantir uma identidade singular desta instituição de ensino, pautada nos princípios constitucionais da cidadania e da dignidade da pessoa humana. Seu principal objetivo é oportunizar aos educadores e educandos a construção coletiva de conhecimentos científicos e culturais, utilizando o regimento escolar e tendo por base os Parâmetros Curriculares Nacionais para a formação de cidadãos comprometidos, empreendedores, responsáveis e conscientes do seu papel na sociedade. 


\section{MATERIAIS E MÉTODOS}

Após revisão bibliográfica e documental realizada em março de 2016 a fim de fundamentar o estudo, foi submetido o Projeto de Pesquisa ao Comitê de Ética na Pesquisa - CEP (CAAE - 53256416.3.0000.5111), sendo aprovado. A coleta de dados aconteceu no mês de abril de 2016. Os dados obtidos foram analisados sob a luz da fundamentação teórica escolhida e a análise dos dados foi realizada com o auxílio de planilha do Excel, que permitiu a tabulação dos resultados e a elaboração de gráficos para evidenciar os resultados.

Foram aplicados quatro questionários, sendo dois deles destinados aos professores civis e militares do Ensino Fundamental e Médio, um para monitores militares do Ensino Fundamental e Médio e outro para alunos do 70 ano do Ensino Fundamental do CMDP II. Os itens que compuseram os questionários pretendiam identificar os participantes da pesquisa, profissionais e alunos envolvidos nos diversos processos organizacionais que podem contribuir com a inclusão.

Os sujeitos da pesquisa foram divididos em 53 professores civis e militares, correspondendo a todos os profissionais da Educação Básica; 20 monitores militares que atuam nas séries iniciais do Ensino Fundamental e Médio, composta por praças do CBMDF (soldados e sub tenentes), que passam por um processo de seleção realizado pelo SOEPAS para certifi- cação de perfil; e, 33 alunos da turma do 70 ano do ensino fundamental (nove anos de idade) pelo fato de estarem há pelo menos três anos na escola e pela possibilidade de ainda permanecerem pelo menos por mais cinco anos

Após delimitação dos sujeitos envolvidos na pesquisa, foram aplicados os questionários junto aos professores e aos monitores individualmente. Na segunda fase da pesquisa, o questionário foi aplicado aos alunos do 7으 ano, coletivamente em sala de aula.

Por fim, com a análise pronta, foram propostas discussões dirigidas com os gestores da escola e com toda a equipe pedagógica que ocorreu durante o ano letivo no intuito de disseminar os princípios da educação inclusiva no âmbito escolar.

\section{RESULTADOS E DISCUSSÃO}

Destaca-se que todos os professores da instituição possuem no mínimo a graduação, sendo que $68 \%$ deles possuem especialização e $6 \%$ mestrado. Os dados apontam a busca pela formação continuada dos profissionais da escola. Ressalta-se que 46\%, 24 docentes possuem vínculo a pouco tempo na escola, menos de 3 anos, merecendo um maior acompanhamento e formação continuada para que compreendam e vivenciem os valores institucionais. Na Tabela 1 é possível perceber os resultados referentes ao perfil dos professores que atuam na escola.

Tabela 1: Perfil dos professores

\begin{tabular}{|l|c|c|c|}
\hline QUESTÕES OBJETIVAS & OPÇÃO 1 & OPÇÃO 2 & OPÇÃO 3 \\
\hline 1. Qual o tempo de atuação no CMDPII? & De 1 a 3 anos & De 4 anos à 7 anos & Mais de 8 anos \\
\hline 2. Qual a sua formação pedagógica? & $46 \%$ & $21 \%$ & $33 \%$ \\
\hline $\begin{array}{l}\text { 3. Quantos cursos de aperfeiçoamento na } \\
\text { área da educação especial e/ou inclusão? }\end{array}$ & Genhum & De 1 a 3 & Mais de 3 \\
\hline $\begin{array}{l}\text { 3.1 Você acredita na inclusão dos alunos } \\
\text { com necessidades educacionais especiais } \\
\text { no ensino regular? }\end{array}$ & Sim & Pós-Graduação & Mestrado \\
\hline & $64 \%$ & Não & $17 \%$ \\
\hline
\end{tabular}

Fonte: elaborado pelos autores 
Outro ponto que merece destaque é que 19 (36\%) professores alegam não possuir cursos específicos para atender a diversidade humana na escola, o que poderia garantir um processo de inclusão mais efetivo.

Ressalta-se que 64\% dos docentes alegam acreditar na inclusão e $36 \%$ sinalizam acreditar em parte, dessa forma pode-se detacar que ações pontuais e acertivas podem corroborar com a eliminação da barreira atitudinal, fazendo com que os profissionais compreendam o processo e assumam postura proativa na garantia da inclusão escolar no universo da CMDPII. Outro aspecto considerável está evidenciado na Figura 1, indicando que a maioria optaria em trabalhar com estudantes especiais.

Verificou-se que apenas 8\% dos entrevistados declararam ter recebido algum tipo de formação e suporte para trabalhar com os alunos especiais, o que evidencia uma necessidade de redirecionamento das ações pedagógicas dentro da instituição de ensino em vista de romper barreiras e promover uma acessibilidade comunicacional e atitudinal que rompa com comportamentos associados a exclusão escolar.

De acordo com os dados apresentados, é demonstrado que o CMDPII ainda necessita melhorar suas estruturas físicas e adequá-las as necessidades dos estudantes.

Em relação ao desenvolvimento do estudante, a Figura 2 apresenta a acessibilidade atitudinal presente na relação professor/aluno.

Figura 1: Verificação dos aspectos atitudinais acerca da inclusão

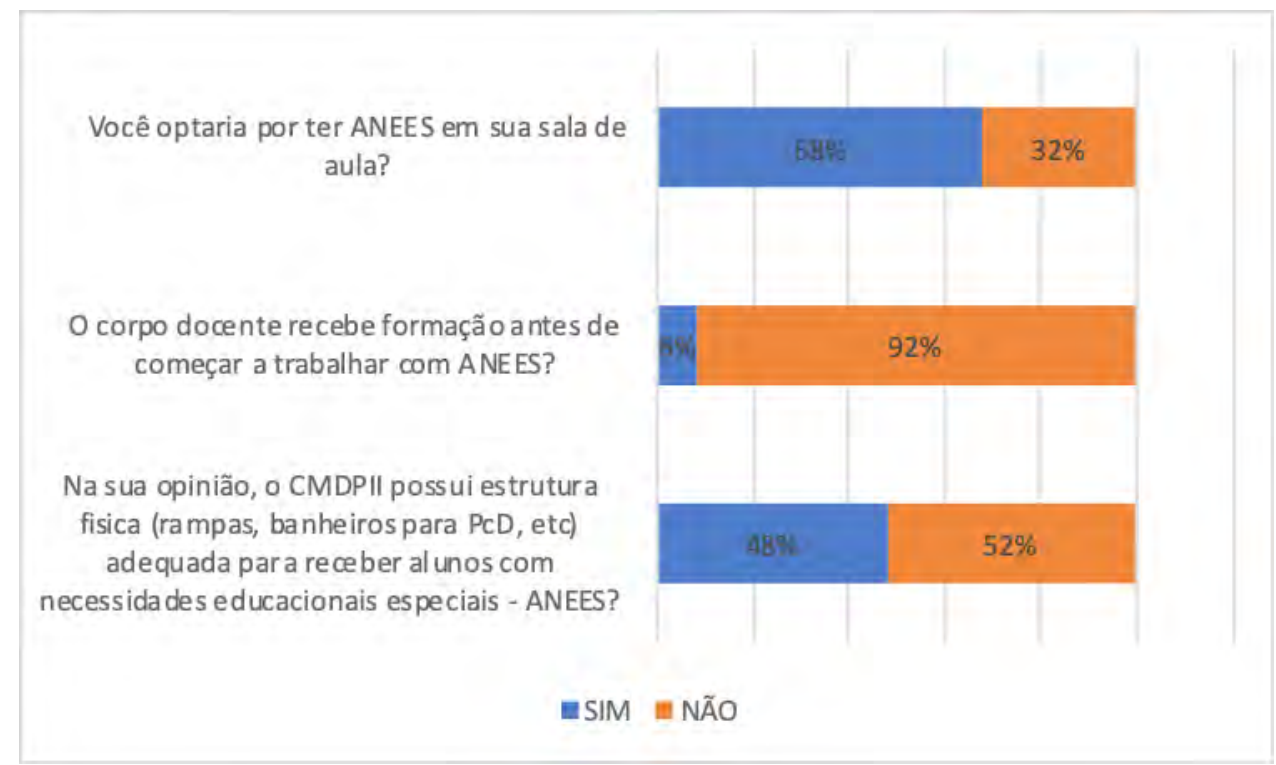

Fonte: elaborado pelos autores. 
Figura 2: Desenvolvimento do Estudante

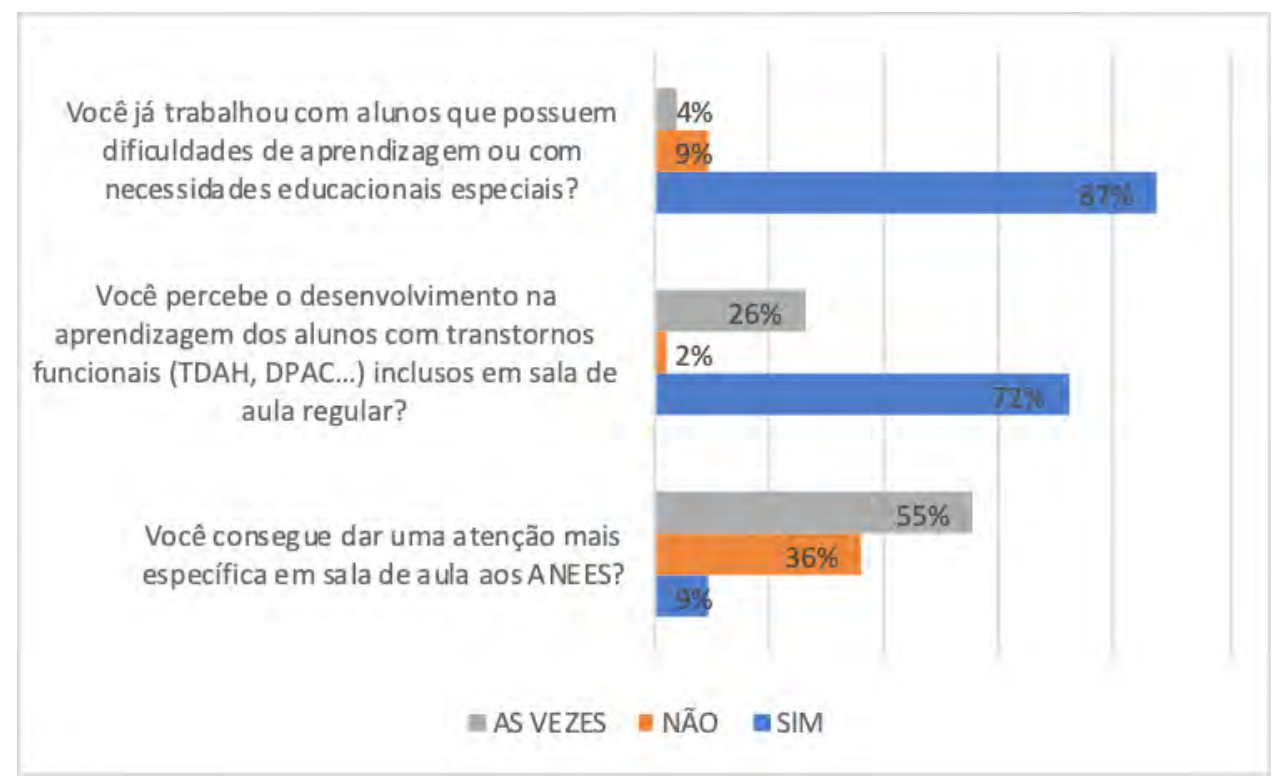

Fonte: elaborado pelos autores.

Evidencia-se que $87 \%$ dos professores já trabalharam com alunos com algum tipo de deficiência. Nessa linha, comparando os dados da figura 1, percebe-se que os professores possuem conhecimento da educação especial e inclusiva e reconhecem que os estudantes podem se desenvolver adequadamente com a postura inclusiva presente na comunidade escolar. Por sua vez, o questionário possuía uma questão aberta com a seguinte proposição: "Sugestão de trabalho para favorecer a inclusão dos ANEEs (Alunos com necessidades educacionais especiais) no CMDP II". No espaço destinado as respostas dessa questão, foi possível observar o discurso dos sujeitos quanto ao tema proposta, sendo que eles descreveram suas opiniões e sugestões para melhoria do processo educacional inclusivo no CMDP II.

Entre as contribuições, destaca-se:

1. "Fornecer preparação adequada para os professores que têm ANEEs em sala".

2. "Sala de apoio especializadas, salas de aula com menos alunos, adequação curricular, monitores nas situações que necessitem".
3. "Instituição de ensino com estrutura, profissionais especializados e cursos de aperfeiçoamento e avaliação continuada relativa à inclusão".

4. "Orientar a comunidade escolar, em especial os docentes, quanto à limitação dos alunos para que os métodos sejam aplicados com eficiência".

5. "A principal sugestão é que os professores tenham apoio dentro de sala e fora de sala, pois muitas vezes o professor não tem suporte e acaba sem saber como lidar com aquele aluno".

6. "Com urgência uma sala de recursos com profissionais capacitados e disponíveis para trabalhar com os alunos ANEES em horário contrário à aula.

Os pontos esboçados pelos professores, evidencia a necessidade de intensificação na formação dos profissionais, como também a necessidade de melhor aparelhar a escola para o processo, inclusive com a implantação de salas de recursos para atendimento aos alunos e suporte aos professores. A Figura 3 traz outras questões respondidas pelos professores: 
Figura 3: Questionário de percepção de docentes

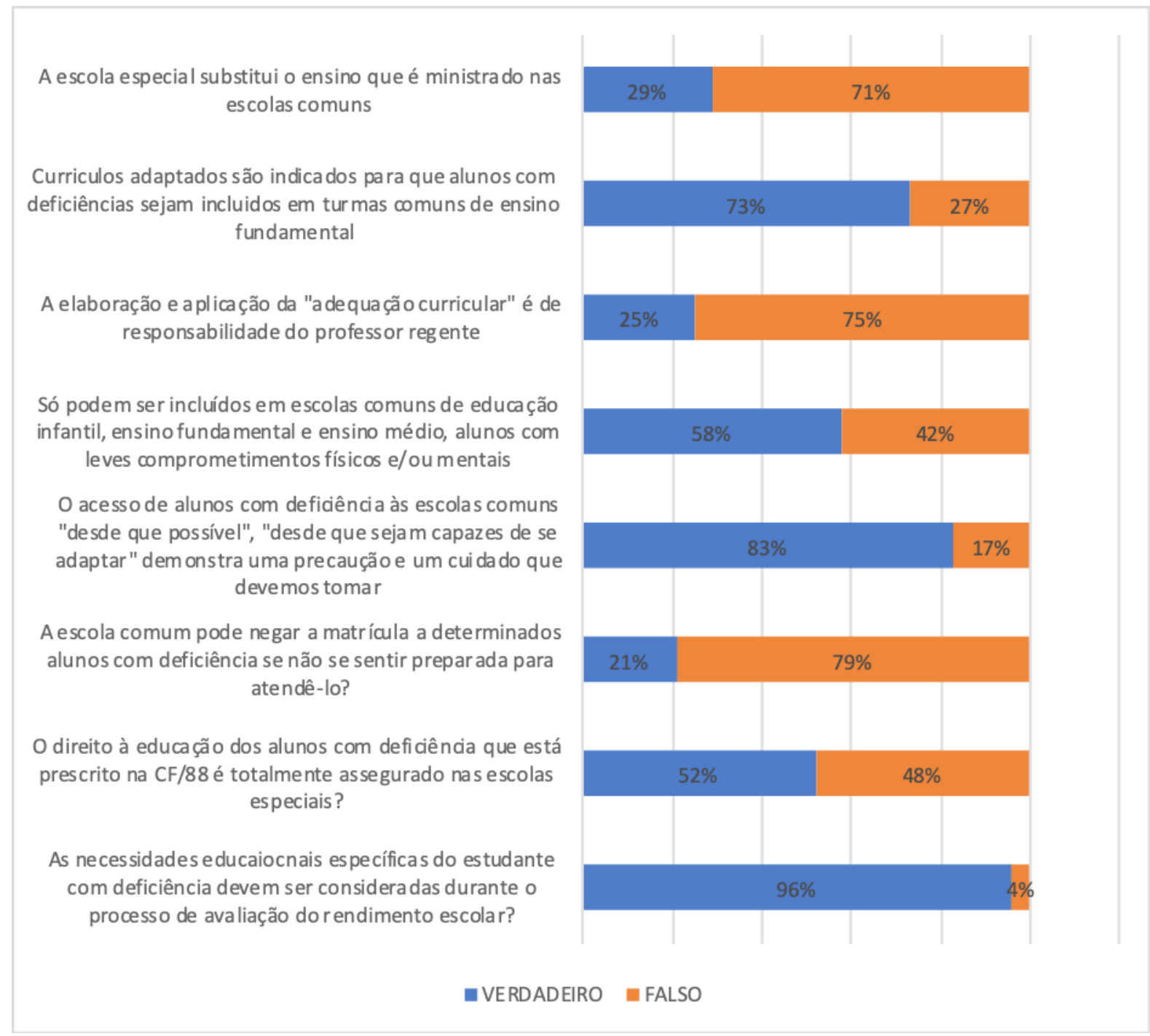

Fonte: elaborado pelos autores.

A pergunta 1 levantou um ponto importante para análise e demonstrou que um percentual relevante, $29 \%$, acredita que a escola especial substitui o trabalho a ser executado nas escolas comuns. Assim, evidencia o desconhecimento de que o princípio da inclusão traz a tona o fato de que todos os alunos devem conviver no mesmo espaço físico, contudo, com recursos diferenciados que garanta o pleno desenvolvimento biopsicosocial.

A análise das questões revelou a necessidade de realização de oficinas pedagógicas que promovam a reflexão e a eliminação de barreiras atitudinais e comunicacionais que dificultam a inclusão. Formações específicas referentes a adequação e flexibilização curricular, avaliação dianóstica, formativa e continuada, adequação dos espaços e tempos escolares, entre outras.

Ressalta-se que na questão 6 apontada na Figura 8 , ainda existem profissionais que alegam a legalidade na negação da matrícula em escola comum para pessoas com deficiências, na hipótese da escola se sentir incapaz de oferecer atendimento com qualidade. Vale destacar que tal posicionamento demonstra ferir o preceito legal e os marcos da inclusão, sobretudo a concepção de a escola é para todos.

Por sua vez, existe a concepção, evidenciada por $48 \%$ dos sujeitos, de que a escola especial garante o preceito de direito a educação (Carta Magna), quan- 
do o aluno está matriculado em escola especial. Destaca-se que o aluno tem direito a educação em escola comum, espaço este que deve oferecer todo o suporte para o êxito, no processo escolar, de todas as pessoas.

Por sua vez, na questão de número 8 (FIGURA 3), é revelado que $96 \%$ dos professores percebem a avaliação como ferramenta para identificação do rendimento do aluno, portanto, fortalecem a importância da coerência que deve existir na mesma, sendo ela diagnóstica, formativa e processual.

Como detalhado na metodologia, foi aplicado um questionário aos monitores da escola, na Tabela 2, o condensado das respostas desses profissionais.

Tabela 2: Questionário de percepção de monitores

\begin{tabular}{|c|c|c|c|}
\hline QUESTÕES OBJETIVAS & OPÇÃO 1 & OPÇÃO 2 & OPÇÃO 3 \\
\hline \multirow[t]{2}{*}{ 1. Qual seu tempo de atuação na monitoria? } & De 1 a 3 anos & $\begin{array}{c}\text { De } 4 \text { a } 7 \\
\text { anos }\end{array}$ & Mais de 8 \\
\hline & $30 \%$ & $30 \%$ & $40 \%$ \\
\hline \multirow[t]{2}{*}{ 2. Possui algum curso na área de educação? } & Nenhum & De 1 a 3 & Mais de 3 \\
\hline & $60 \%$ & $40 \%$ & $0 \%$ \\
\hline \multirow[t]{2}{*}{$\begin{array}{l}\text { 3. Você disponibilizaria tempo para realizar } \\
\text { curso na área da educação inclusiva? }\end{array}$} & Sim & Não & $\mathrm{X}$ \\
\hline & $68 \%$ & $32 \%$ & $\mathrm{x}$ \\
\hline \multirow[t]{2}{*}{ 4. Você já prestou algum apoio à ANEEs? } & Sim & Não & $\mathrm{X}$ \\
\hline & $55 \%$ & $45 \%$ & $\mathrm{x}$ \\
\hline \multirow[t]{2}{*}{$\begin{array}{l}\text { 5. Você acredita na inclusão dos alunos com } \\
\text { ANEEs na escola comum? }\end{array}$} & Sim & Não & Em parte \\
\hline & $45 \%$ & $20 \%$ & $35 \%$ \\
\hline \multirow[t]{2}{*}{$\begin{array}{l}\text { 6. Na sua opinião, o CMDPII possui estrutu- } \\
\text { ra física (rampas, banheiros para deficientes, } \\
\text { etc.) adequada para os ANEEs? }\end{array}$} & Sim & Não & $\mathrm{X}$ \\
\hline & $30 \%$ & $70 \%$ & $\mathrm{x}$ \\
\hline \multirow[t]{2}{*}{$\begin{array}{l}\text { 7. Você acha que uma criança com ANEEs } \\
\text { aprende e ensina com as outras crianças? }\end{array}$} & Sim & Não & Em parte \\
\hline & $55 \%$ & $5 \%$ & $40 \%$ \\
\hline \multirow[t]{2}{*}{$\begin{array}{l}\text { 8. Só podem ser incluídos em escolas co- } \\
\text { muns alunos com leves comprometimentos } \\
\text { e os com graves deficiências devem continu- } \\
\text { ar nas escolas especiais. }\end{array}$} & Sim & Não & $x$ \\
\hline & $95 \%$ & $5 \%$ & $x$ \\
\hline
\end{tabular}

Fonte: elaborado pelos autores 
No condensado é possível perceber a necessidade de formação desses profissionais, visto que é evidente que muitos deles não conhecem os preceitos básicos da inclusão, na questão 8 fica claro tal fato, já que 95\% dos sujeitos alegam que as escolas comuns devem receber apenas pessoas com deficiências consideradas leves. Também é importante destacar que $60 \%$ desses monitores reforçam não possuir cursos na área da educação.

Outro ponto que merece observação é a que se re- laciona com a acessibilidade arquitetônica, já que $70 \%$ desses sujeitos alegam que a escola não possui acessibilidade adequada.

Por sua vez, na tabela 3 é demonstrado, na visão dos monitores, os fatores que dificultam a inclusão, com destaque para qualificação, formação, estrutura física e número de alunos por sala. Tais evidências apontam a necessidade de se garantir a acessibilidade, seja ela, arquitetônica, comunicacional e atitudinal.

Tabela 3: Fatores dificultadores da inclusão educacional

\begin{tabular}{|c|c|c|c|}
\hline $\begin{array}{l}\text { Falta de profissionais } \\
\text { qualificados para avaliar } \\
\text { as Especificidades }\end{array}$ & $\begin{array}{l}\text { Falta de cursos de } \\
\text { aperfeiçoamento }\end{array}$ & $\begin{array}{l}\text { Falta de estrutu- } \\
\text { ra física adequa- } \\
\text { da para os alunos } \\
\text { com deficiências }\end{array}$ & $\begin{array}{l}\text { Excesso de alunos ma- } \\
\text { triculados por turma }\end{array}$ \\
\hline $30 \%$ & $23 \%$ & $27 \%$ & $20 \%$ \\
\hline
\end{tabular}

Fonte: elaborado pelos autores

Vale destacar que os monitores possuem maior tempo de atuação na instituição, se comparado à análise dos dados pesquisados junto aos professores. Também destaca-se que a maioria não possui nenhum curso na área, o que pode dificultar sua atribuição de prestar suporte ao corpo discente.

Verifica-se que a maioria dos monitores demonstraram interesse em realizar cursos na área da educação especial. Também é evidente a necessidade de sensibilização pedagógica junto a esse grupo, já que demonstram não conhecer os fundamentos relativos a inclusão.

Assim sendo, é perceptível nas respostas de professores e monitores a necessidade de capacitação para a inclusão, passando pelos sustentação teórica relativa ao tema, como também, reflexões a paritr da prática profissional, o que poderá favorecer a reflexão na ação.

Ainda em relação aos monitores, o questionário possuía uma questão aberta que buscava levantar sugestões para favorecer a inclusão na escola, sendo as seguintes respostas obtidas:
- Divulgação da necessidade de inclusão, maior apoio dos órgãos de gestão promovendo a inclusão com atividades, palestras, seminários e "workshop" para estes alunos (MONITOR 1).

- Escola adequada e profissionais qualificados de acordo com cada necessidade especial (MONITOR 2).

- Adaptar os banheiros, contratar professores na área, etc. (MONITOR 3).

- Melhoria da estrutura para atendimento dos alunos, proporcionalidade entre o número de alunos com ANEES e professores qualificados na área (MONITOR 4).

- Profissionais qualificados ou especializados, promover cursos de aperfeiçoamento, construir uma estrutura física (MONITOR 5).

Sendo assim, da mesma forma que o percebido entre os professores, percebe-se a necessidade de fortalecimento das práticas inclusivas, como também a 
formação profissional, no âmbito da CMDPII. Por sua vez, a Tabela 4 apresenta o resultado referente a aplicação do questionário junto aos alunos do CMDPII, ou seja:

Tabela 4: Questionário de percepção de discentes

\begin{tabular}{|l|c|c|c|}
\hline \multicolumn{1}{|l|}{ QUESTÕES OBJETIVAS } & OPÇÃO 1 & OPÇÃO 2 & OPÇÃO 3 \\
\hline 1. Você sabe o que é Escola Inclusiva? & Sim & Não & Em Parte \\
\hline $\begin{array}{l}\text { 2. O que você acha de receber na escola } \\
\text { alunos com deficiência? }\end{array}$ & $46 \%$ & $39 \%$ & $15 \%$ \\
\hline & Bom & Ruim & X \\
\hline $\begin{array}{l}\text { 3. A interação com alunos com deficiência } \\
\text { pode trazer algum benefício para a sua vida? }\end{array}$ & Sim & Não & Não Sei \\
\hline $\begin{array}{l}\text { 4. Em sua escola, seus colegas têm algum } \\
\text { preconceito em relação aos ANEEs? }\end{array}$ & $64 \%$ & $3 \%$ & $33 \%$ \\
\hline $\begin{array}{l}\text { 5. Na sua opinião, o CMDPII possui estrutu- } \\
\text { ra física (rampas, banheiros para deficientes, } \\
\text { etc.) adequada para os ANEEs? }\end{array}$ & Sim & Não & Às Vezes \\
\hline $\begin{array}{l}\text { 6. Você aceita que os ANEEs participem das } \\
\text { mesmas atividades recreativas que você? }\end{array}$ & Sim & Não & X \\
\hline $\begin{array}{l}\text { 7. Você acha que uma criança com deficiên- } \\
\text { cia aprende e ensina com as outras crianças? }\end{array}$ & Sim & Não & Às Vezes \\
\hline & $85 \%$ & $3 \%$ & $12 \%$ \\
\hline
\end{tabular}

Fonte: elaborado pelos autores

As respostas dos 33 alunos do 70 ano, demonstram que existe uma excelente aceitação por parte dos discentes no que se refere a inclusão da pessoa com deficiência em sua sala, já que eles, quase na sua totalidade, acham adequado receber pessoas com deficiências em suas turmas, aceitam que essas pessoas participem das mesmas atividades na escola, acreditam que podem aprender e ensinar participando e convivendo com outras crianças.
Ressalta-se que a maioria dos estudantes ainda não sabem o que significa educação inclusiva, no entanto demonstram-se abertos ao processo. Como professores e monitores, os estudantes também percebem que a escola precisa adequar suas instalações físicas para atender às reais necessidades dos estudantes. Outro aspecto significativo é que entre os estudantes há uma boa aceitação e interação com aqueles com necessidades especiais, e a maioria reconhece que as diferenças contribuem para o desenvolvimento das aprendizagens. 


\section{CONSIDERAÇÕES FINAIS}

Durante a realização da pesquisa de campo na escola, foi possível observar que em algumas seções do CMDP II foram criadas Normas Gerais Administrativas para atender à realidade atual, considerando que o Regimento Interno do CMDP II e o Manual do aluno precisam ser reformulados para atender às necessidades atuais de organização e funcionamento, já que o atual não faz menção aos ANEEs.

Como o Projeto Político Pedagógico do CMDPII não traz em seu texto referências sobre adequações curriculares e não se encontra baseado nos princípios da educação inclusiva, considerando que o PPP é datado de 2011, sugere-se adequar tal instrumento a realidade atual.

Da mesma forma, atendendo ao objetivo do estudo, buscou-se apresentar aos gestores da escola a necessidade de reformulação e adequação das diretrizes pedagógicas, a adequação dos espaços físicos, ampliação e socialização do conhecimento, a mudança de postura e a criação de um grupo de estudo que possa rever práticas, aprofundar conhecimentos e trocar experiências.

Rever a estrutura da instituição de forma a subsidiar novas ações que respondam às demandas apresentadas pela coleta de dados junto aos professores, monitores e alunos da escola, tornou-se objeto a ser perseguido.

Por sua vez, a pesquisa permitiu o mapeamento institucional, a análise dos resultados por seguimento, a análise do PPP, a verificação da estrutura arquitetônica. Verificou-se que, concomitantemente à realização da pesquisa, foi fomentado dentro da instituição de ensino um maior interesse pelo tema, sendo que os resultados apresentados junto a direção, professores e monitores, subsidiaram novas ações de fortalecimento das práticas pedagógicas, atendendo aos princípios da Educação Inclusiva.

É possível afirmar que o estudo deixou claro que a estrutura física da escola precisa de adequações, faz-se necessário reduzir o número de alunos por sala, existe ainda, certa insuficiência de conhecimento dos aportes conceituais e da aplicabilidade de metodolo- gias inclusivas que respondam às reais necessidades educacionais dos alunos.

Como limitações da pesquisa destaca-se principalmente o caráter peculiar da instituição de ensino pesquisada. Trata-se de uma escola com característica híbrida - pública e privada - subordinada à Diretoria de Ensino e sob administração do Corpo de Bombeiros Militar do Distrito Federal (CBMDF). Esse fator dificultaria sua replicabilidade em outras instituições de ensino que não possuem essa especificidade.

Por fim, ressalta-se que o PPP se encontra desatualizado, no entanto tal instrumento garante a formação continuada para os profissionais, faz referência ao investimento financeiro no que tange a capacitação, o que pode viabilizar a oferta de cursos na área. Nesse contexto, como sugestão de futuras pesquisas, entende-se que esse estudo poderá subsidiar o redirecionamento das práticas pedagógicas inclusivas do CMDP II.

\section{REFERÊNCIAS}

BRASIL. Lei no 7.853, de 24 de outubro de 1989. Disponível em: http://www.planalto.gov.br/ccivil 03/leis/ L7853.htm, acesso em 26/10/2017.

Nota Técnica № 04 - Orientação quanto a documentos comprobatórios de alunos com deficiência, transtornos globais do desenvolvimento e altas habilidades/superdotação no Censo Escolar. 2014. Disponível em: http://portal.mec.gov.br/ index.php?option=com_docman\&view=download\&alias=15898-nott04-secadi-dpee-23012014\&category_slug=julho-2014-pdf\&Itemid=30192, acesso em 13/08/2019.

Lei no 13.005, de 25 de junho de 2014. Aprova o Plano Nacional de Educação - PNE e dá outras providências. 2014a. Disponível em: http://www.planalto.gov.br/ccivil 03/ ato2011-2014/2014/lei//13005. $\underline{\mathrm{htm}}$, acesso em 26/10/2017.

Declaração de Salamanca e linha de ação sobre necessidades educativas especiais. Brasília: UNESCO, 1994b.

Lei no 9394/96. Lei de Diretrizes e Bases da Educação. Brasília: MEC/ SEE, 1996. 
[Constituição (1988)]. Constituição da República Federativa do Brasil. 43. ed. - Brasília: Câmara dos Deputados, Edições Câmara, 2015.

[Estatuto da criança e do adolescente (1990)]. Estatuto da criança e do adolescente [recurso eletrônico]: Lei n. 8.069, de 13 de julho de 1990, e legislação correlata. - 14. ed. - Brasília : Câmara dos Deputados, Edições Câmara, 2016.

CBMDF. Portaria no 021/CBMDF de 07 de julho de 2000- Regimentos Interno e Escolar do. Boletim Geral-BG n128 do CBMDF. 2000.

DISTRITO FEDERAL. Lei no 2393, de 07 de junho de 1999. Cria o Colégio Militar Dom Pedro II, na área da Academia de Bombeiros Militar do Distrito Federal. 1999. Disponível em: http://www.tc.df.gov.br/SINJ/ Norma/50351/Lei 23930706 1999.html, acesso em 26/10/2017.

Decreto $n^{\circ} \mathbf{2 1 . 2 9 8}$, de 29 de junho de 2000. Dispõe sobre a regulamentação da Lei Distrital $n .{ }^{\circ}$ 2.393 de 07 de junho de 1999, que cria o Colégio Militar Dom Pedro II na área da Academia de Bombeiros Militar do

Distrito Federal e dá outras providências. 2000. Disponível em: http://www.cmdpii.com.br/images/legislacao-pdf/decreto-n-21298-de-29-de-junho-de-2000. pdf, acesso em 26/10/2017.

MANTOAN, M. T. E; PRIETO, R. G. Inclusão escolar: pontos e contrapontos. São Paulo: Summus, 2006.
MAZZOTA, M. J. Educação Especial no Brasil: história e políticas públicas. São Paulo: Cortez, 1995.

MEIRIEU, P. A Pedagogia entre o Dizer e o Fazer. Porto Alegre: Artmed, 2002.

MOREIRA, A. M. e CHAMON, E. M. Q. O. Ser Professor: Representação Social e Construção Identitária. Curitiba, Appris, 2015.

NEVES, L. R; RAHME, M. M. F. e FERREIRA, C. M. da R. J. Política de Educação Especial e os Desafios de uma Perspectiva Inclusiva. Educ. Real. [online]. 2019, vol.44, n.1. Disponível em: http://www.scielo.br/scielo.php?script=sci_abstract\&pid=S2175-62362019000100203\& Ing=en\&nrm=iso/\&tIng=pt, acesso em 13/08/2019.

PRIOSTE, C. D. Diversidade e Adversidades na Escola: queixas e conflitos de professores frente à educação inclusiva. 2006. Dissertação (Mestrado em Educação) - Faculdade de Educação, Universidade de São Paulo, São Paulo, 2006.

VOLTOLINI, Rinaldo. Interpelações Éticas à Educação Inclusiva. Educ. Real. Porto Alegre, v. 44, n. 1, e84847, 2019 . Disponível em: <http:// www.scielo.br/scielo.php?script=sci_arttext\&pi$\mathrm{d}=$ S2175-62362019000100204\&lng=en\& $\mathrm{nrm}=$ iso >. Acesso em 13/08/2019. 